Psychology of Language and Communication 2015, Vol. 19, No. 1

\author{
ADAM KUCHARSKI, CELINA TIMOSZYK-TOMCZAK \\ University of Szczecin
}

\title{
APPRECIATION OF AMBIGUOUS HUMOROUS MESSAGES: THE INFLUENCE OF PROCESSING MODE AND PRESENTATION
}

\begin{abstract}
In the current study it was assumed that participants of the act of communication do not always follow the rules of cooperation, and sometimes build their utterance in a way that misleads the listener. It depends on the communicative competence of the listener and the message sender if an interaction between them takes place. The aim of this research was to assess to what extent deliberate, incorrect identification and the mode of communication in which the text is presented makes the audience lose their orientation in both bona-fide (informative) and non-bona-fide (playful) mode formulations. In order to answer these questions, two experiments were conducted using three types of texts: informative text with a humorous digression, humorous informative text, and a real life parody joke. The information preceding the presentation of the texts and the order in which they were shown was manipulated. Respondents assessed how funny each of the texts was. 85 high secondary school students participated in the survey. The conducted statistical analyses enabled us to establish that the information appearing at the beginning, i.e. the type of message (informative/humorous), can affect the recipient's reaction and assessment of how funny a particular text was. The research results indicate that poor intensity of comicality in the messages may be aggravated by not indicating that they were intended to induce a humorous effect. This reveals the specific nature of humorous messages, bringing about an effect that is categorically inconsistent with the stimulus that precedes it.
\end{abstract}

Key words: humour, bona-fide communication, non-bona fide communication, informative precedence, humour appreciation, humour competence

Etymologically, the meaning of the term 'to communicate' is derived from the latin word 'communicare', which means 'to be in relation (connection) with', 'to participate in', or 'to form a union'.

There are almost as many definitions of communication as there are authors addressing this subject matter. Communication is understood as: transmission,

Address for correspondence: Adam Kucharski, Faculty of Psychology of the University of Szczecin, Krakowska 69, 71-017 Szczecin, Poland. E-mail: kadam72@gazeta.pl 
process, speech, understanding, symbol, channel, connection, influence, or exchange (Goban-Klas, 2009; Morreale, Spitzberg, \& Barge, 2011). Fiske (2003) groups the theories of communication into those that concentrate on the process of communication and into those that draw attention to the generation of communication. In an analysis of different definitions of communication, DobekOstrowska (2011) points out that they do not oppose each other, but emphasize different elements. According to Morreale, Spitzberg, \& Barge (2011), we can differentiate four models of communication, understood as transfer of information, agreement on a meaning, persuasion, or forming a community.

These authors observe that one model is not sufficient to explain the process of communication, as some situations in social life require an agreement on the meaning of a message while others show an ambiguity of the communicated information, for example when the aim of communication is to persuade. The model which combines these notions is the model of community, according to which our means of communication influence the quality of our life, relationships, and communities. It requires an adequate choice of the form of communication, which is possible if we possess communicative competence. This model can therefore be defined as the model of communicative competence. Communicative competence implies the use of verbal/nonverbal behaviour in order to achieve the chosen aims by a means adapted to the context. There are three standards of communicative competence: clarity, appropriateness, and effectiveness. Clarity means the comprehensibility and explicitness of the content, although even precise messages do not always meets with understanding. Sometimes, even if the content was understood by the sender, the recipient does not agree to ascribe the relevant meaning to it. Furthermore, clarity is sometimes a means to achieve another aim. The aim is rarely limited exclusively to the understanding of the message content.

Appropriateness means to communicate in a manner adequate to the given context, without violating norm based rules. When a rule is broken, sanctions follow in the form of the return information. Effectiveness describes the degree to which the communication succeeds in achieving the expected result. The effectiveness of communication is closely related to the notion of purpose.

The authors of this model emphasize that communicative competence consists of a subtle balance between the pursuit of appropriateness and effectiveness. This means that persons with communicative competence are not exclusively set on achieving a result when imparting information or exerting an influence on the recipient, but also strive at the same time to observe the rules that govern interpersonal relationships.

This view is similar to the division proposed by Halliday (1994), who distinguishes two functions of the use of language: ideational and interpersonal. We employ language to describe events, to communicate ideas, and to inform others about our experience and inner feelings. We also use language in order to build positive interpersonal relationships and to influence others. Brown and Yule (1983; 
after: Partington, 2006) make another, identical distinction by differentiating two categories of the use of language. The first - transaction - concerns the effective communication of contents, whereas the purpose of the second - interaction - is to express and maintain social relations. Partington (2006) perceives a similarity with the division proposed by Raskin (Raskin, 1985) into a bona fide mode of communication, the purpose of which is to impart true information, and a non-bona fide mode of communication. The bona fide mode of communication is governed by the rules suggested by Grice (1980). According to him, speech is a deliberate rational action governed by the Principle of Cooperation and its maxims, which are treated as a quasi-contract. This consists of the definition of a direct common aim and in treating the conversational interests of the other party as one's own. Grice is aware that this aim is secondary, but its consideration conditions the proper progress of the conversation. While pursuing their own, primary aims the participants of a conversation must not forget that the other party also has aims, and granting it the right to realize them while retaining their own is the basis for the proper course of conversation. In addition, there is a need for a mutual connection, an interdependence of the contributions of individual participants. Conversation is a mutual exchange. The burden of conversation cannot therefore rest on only one of the parties. It is necessary to build on what was said and to continue the utterance so that the other participant can take over the burden of conversation. This procedure is continued until both parties acknowledge that further cooperation is unnecessary.

The non-bona fide mode of communication, which includes the telling of jokes, serves other purposes, such as to amuse others or to create a friendly atmosphere, and does not require speaking the truth. The use of this form of communication to the above purpose relies on humour competence (Raskin, 1985). Raskin (1985) defines it as a universal human quality and regards the differences between people in their sense of humour as mostly quantitative in character.

\section{Communicative competence versus joke competence and humour competence}

The above considerations lead to the differentiation of two modes of communication, of which one is governed by the rules of Grice (1980) and the other is defined by the rules of Raskin (1985). The use of the non-bona fide mode of communication requires communicative competences composed of joke competence and humour competence (Carrell, 2000). It is necessary to possess joke competence (of a humorous text) in order to categorize the text as humorous. This is, however, not equivalent with a high assessment of its funniness. The recipient may find the joke funny in a certain situation but not in another, although this does not mean that they did not recognize it as a joke. They then probably treat it as devoid of humorous qualities. Carrell (2000) thinks that joke 
competence is a relatively static, elementary construct. Of a different nature is humour competence, which Carrell defines as a dynamic construct formed by individual, random events, often determined by the situation in which the joke is told. Both constructs make up the communicative competence, which is used unconsciously. The recipient only sometimes, when the text is untypical, consciously initiates the process of identifying the text as a joke by asking if they are dealing with a joke. If the answer is yes, then the text is accepted as being of a potentially humorous character. If the text is not categorized as a joke then humorous treatment of it will be impossible. The text will be processed in the bona fide mode or as not suited to the ongoing discourse.

We can distinguish two main reasons why a joke may not be recognized as a joke. One is lack of practice, due to which the recipient does not recognize the joke. The other is the lack of available scripts, which makes the understanding of the text impossible. If the recipient succeeds in recognizing the text as joke, then they will directly pass from processing it in the bona fide mode to processing it in the non-bona fide mode. There may, of course, also be situations in which the intention of the sender was not to make a humorous utterance but was nevertheless identified as one by the recipient. The sender can then try to correct this interpretation, although it is usually too late for that. Humorous competence activated in the non-bona fide mode depends mainly on the availability of scripts based on which the joke was classified in the bona fide mode, i.e. according to joke competence as a humorous text (joke). The activation of humour competence can have three basic results. The joke can be funny and therefore amuses the recipient. It is also possible that the joke is funny and the recipient does not fully recognize the scripts, but is inclined to search for the comicality in the joke. They would then ask for additional information and attempt once more to process the text using the available humour competence. Lastly the joke may not be funny, which means that the recipient does not recognize the scripts in the joke and does not want to make the effort to deploy humorous competence. They may treat the joke as not very surprising because it is already known, or perhaps imply that it is too complicated and therefore not properly understood.

\section{Problems with the non-bona fide mode of communication}

However, the sender will not always define the mode of communication. They will not always announce a forthcoming joke, nor will they give any nonverbal messages to indicate this intention. This has its positive aspects, as it allows in many situations to avoid a confrontation between the sender and the recipient. Should the discourse participants decide to conduct their conversation in the bona fide mode, this could lead to an endless exchange of arguments and counterarguments. By immediately referring to a communication in the non-bona fide mode, it will remain possible to withdraw from the adopted standpoint by 
saying that „it was just a joke”. A problem arises when the intention was clearly stated, but the utterance is nevertheless classified wrongly by the recipient. Raskin (1985) distinguishes four situations which define the relations between the sender and the recipient: (1) the sender intentionally makes a joke and the recipient anticipates it (2) the sender intentionally makes a joke and the recipient does not expect it, (3) the sender unintentionally makes a joke and the recipient expects it, and (4) the sender unintentionally makes a joke and the recipient does not anticipate it.

The first situation is a case in which the sender precedes their humorous utterance with a clear and open cue that they are going to tell a joke. The purpose of such an introduction is to establish the mode of communication and to pass from the bona fide mode to the non-bona fide mode. The second assumes that, in daily life, people do not always inform their recipients beforehand that they are going to tell a joke. Often someone tells a joke spontaneously during a conversation in reaction to present events. The joke is then deliberate, but not planned. The third situation can be observed when the sender is manipulated into a humorous situation, which is for example the case when a message is not interpreted in accordance with the intention of the sender. Only the recipient discovers the additional meanings of the scripts used in the utterance. The fourth situation can arise accidentally, without the sender's intention and without the recipient anticipating it as such. This is characteristic of situational humour, e.g. the sender unexpectedly sticks out their tongue and the situation is in itself funny (Zajdman, 1992), or starts laughing because they perceived another meaning in the utterance.

Most important in the process of communication is agreement on the mode of communication between the sender and the recipient. However, sometimes one of the participants violates the transition from the bona fide mode to the non-bona fide mode, which may result in mutual frustration and misunderstanding. A delay occurs when the recipient realizes too late that the message was a joke, but also when the answer of the recipient comes too late. Sometimes the recipient deliberately refuses to proceed to the non-bona fide mode.

Zajdman (1992) provides a compilation of humorous acts and the effects resulting from the appearance of a joke or the lack of one. Examples include situations in which: the sender and the recipient use the bona fide mode (humourless situation; the sender uses the bona fide mode and it is in this mode that the recipient receives the communication, but then perceives a humorous element in the utterance and begins to process the communication in the nonbona fide mode (unintentional humour); the sender uses the bona fide mode and deliberately adds a humorous element in order to shift the conversation into the non-bona fide mode. The recipient, however, is not aware of this and continues to process the information in the bona fide mode, which leads to a misunderstanding; the sender communicates something in the non-bona fide mode and 
the recipient processes it in the same mode by interpreting the intention and the sense of the utterance of the sender; the sender communicates a message in the non-bona fide mode and the recipient understands the intention of the sender and is prepared to process the information in the non-bona fide mode, but fails to see the humorous aspect; the sender uses the non-bona fide mode and this is clear to the recipient, who is prepared to process the utterance in this mode, but interprets the humorous sense of the sender's utterance differently.

The situations presented by Zajdman do not comprise communications in which the sender intentionally constructs their message so that the recipient will not be sure whether to process it in the bona fide or in the non-bona fide mode.

He does, however, add further possible modifications. The sender may, for example, process the communication in the non-bona fide mode, but their intention may be to "slip in" information to be processed in the bona fide mode. The recipient perceives the parallelism of the message, draws the consequences, and processes the content in the non-bona fide mode while reading the content in the bona fide mode. Or, the sender processes the message in the non-bona fide mode, but his intention is to "slip in" information to be processed in the bona fide mode.

\section{Method and objective of our research}

The authors of this study proceed on the assumption that communication participants do not always observe the principles of cooperation and at times, in order to achieve a certain effect, intentionally construct their utterances so that the recipients will be misled. Successful cooperation depends on the communication competence of both the recipient and the sender.

The objective of our research was to estimate to what extent an intentionally misleading indication as to the mode of communication in which a text will be presented makes the recipient lose their orientation of whether the message is formulated in the bona fide (informative) or in the non-bona fide (amusing) mode

To this purpose, the following research question was defined:

1. Is the funniness of texts better appreciated when their presentation is preceded by the information that humorous texts (in the non-bona fide mode) are going to follow, or when the recipients are told that informative texts (in the bona fide mode) will be presented?

In addition, the following question was formulated:

1. Does an announcement concerning the specificity of the mode of communication (bona fide/non-bona fide) influence the appreciation of the funniness of texts as a function of the order of their presentation (joke, humorous presentation of information, informative text with a small dose of humour)? 
In order to provide answers to the above questions, two experiments were conducted using three forms of texts:

1. An informative text with a humorous digression;

2. A humorous informative text parodying real situations;

3. A joke.

In the first experiment the same texts were presented to two groups, beginning with an informative text with a humorous digression and ending with a joke. The members of the first group were informed that they were going to see humorous texts, whereas the members of the second group were told that they were going to see informative texts. After the presentation of each text both groups were asked to assess its funniness.

In the second experiment, the respondents were also divided into two groups. As before, one group was told that it would be shown humorous texts and the second that it would be shown informative texts, but the texts were presented in a different order. The first text to be presented was a joke, the second a humorous informative text, and the last an informative text with a humorous digression. The task of the respondents was to assess their degree of funniness.

85 pupils from a grammar school in Szczecin took part in the research. They were informed of the anonymous character of the research and of the possibility to withdraw from it. Participants received a sheet in order to mark their assessment of how funny each respective text was. The texts were displayed on slides by means of a projector. This was followed by a white screen and a period of time for the respondents to make their assessments.

\section{Analysis of the results}

The statistical analyses showed that preceding information about the type of the text (informative/humorous) can influence the reaction of the recipient and the assessment of the funniness of the given text. The answer to the question "Is the funniness of texts better appreciated if their presentation was preceded by the information that humorous texts (in the non-bona fide mode) are going to follow, or when the recipients are told that informative texts (in the bona fide mode) will be presented?" is very complex.

In the first experiment the texts were presented in the following order: informative text with a small dose of humour, humorous text containing information, and joke (variant I). The obtained results illustrate that assessment of the funniness of the texts was the same for humorous texts containing information and for informative texts with a small dose of humour. The funniness of jokes was more highly appreciated only when the recipients were first informed that they were going to assess an informative text, not a humorous text. 
The identical assessment of informative texts with a small dose of humour and of humorous texts containing information under different experimental conditions is due to the low humorous value of their content. The recipient of such a communication cannot, even if already prepared for the reception of a humorous text and even if this text contains a certain amount of humour, ascribe a high level of funniness to it.

Puzzling, however, is why the funniness of jokes receives higher scores in a situation where there is no conformity between the anticipated type of text (informative) and the actual type of the text (joke). This can also be defined as a divergence between the disposition to process a text in the bona fide mode and the necessity to process it in the non-bona fide mode. This calls to mind an

Table 1. Average assessments of texts preceded by the announcement of an informative text and a humorous text, experiment I

\begin{tabular}{llcccc}
\hline Type of text & $\begin{array}{l}\text { Type of } \\
\text { announcement }\end{array}$ & $N$ & Mean & $\begin{array}{c}\text { Standard } \\
\text { deviation }\end{array}$ & $\begin{array}{c}\text { Standard } \\
\text { error of } \\
\text { the mean }\end{array}$ \\
\hline Informative text & Information & 22 & 1.14 & 0.351 & 0.075 \\
& Humour & 17 & 1.18 & 0.393 & 0.095 \\
Humorous & Information & 22 & 1.73 & 0.767 & 0.164 \\
Informative text & Humour & 17 & 1.71 & 0.849 & 0.206 \\
& Information & 22 & 2.50 & 0.964 & 0.205 \\
& Humour & 17 & 1.53 & 0.717 & 0.174 \\
\hline
\end{tabular}

Table 2. Differences in the assessment of texts preceded by the announcement of an informative text and a humorous text, experiment I

\begin{tabular}{|c|c|c|c|c|c|}
\hline Type of text & $t$ & $d f$ & $\begin{array}{l}\text { Significance } \\
\text { (two-tailed) }\end{array}$ & $\begin{array}{l}\text { Difference of } \\
\text { the means }\end{array}$ & $\begin{array}{c}\text { Standard } \\
\text { error of } \\
\text { the difference }\end{array}$ \\
\hline Informative text & -0.331 & 32.436 & 0.743 & -0.040 & 0.121 \\
\hline $\begin{array}{l}\text { Humorous } \\
\text { informative text }\end{array}$ & 0.081 & 32.662 & 0.936 & 0.021 & 0.263 \\
\hline Joke & 3.605 & 36.967 & 0.001 & 0.971 & 0.269 \\
\hline
\end{tabular}


experiment by Nerhardt (1970) concerning a certain level of incongruence. In Nerhardt's experiment (1970), a series of weights of the same size were presented to the research participants. The last of the weights was always heavier or lighter than the others, although it looked the same. The degree of amusement always increased together with increases in the difference of the weight.

The situation is similar in the current study. A small difference with regard to the form of the message (informative message) and the degree of comicality as between the first two texts does not cause the effect described by Nerhardt (1970). However, a greater divergence, which we can define as incongruence, appears when a recipient who was anticipating an informative message is faced with a typical humorous text.

In the second case, the anticipation aroused by the information about a subsequent humorous text is gradually wiped out by the appearance of an informative text with a small dose of humour. The expectation of the recipient remains unfulfilled, which results in a virtually negative attitude. After the occurrence of the joke, the initial enthusiasm is already abated and the text is more critically assessed than would be the case without previous intervention.

In the second experiment, the order in which the texts were presented was changed. First a joke had to be assessed, then a humorous text containing information, and last an informative text with a small dose of humour. No difference was observed in the assessment of the humorous texts containing information and the informative texts with a small dose of humour. There was, however, a difference in the assessment of the funniness of the jokes. It turned out that jokes received a higher assessment when the respondents were informed that the text to be assessed would be humorous. The results are therefore different than in the first experiment.

Table 3. Average assessments of texts preceded by the announcement of an informative text and a humorous text, experiment II

\begin{tabular}{llcccc}
\hline Type of text & $\begin{array}{l}\text { Type of } \\
\text { announcement }\end{array}$ & $N$ & Mean & $\begin{array}{c}\text { Standard } \\
\text { deviation }\end{array}$ & $\begin{array}{c}\text { Standard } \\
\text { error of } \\
\text { the mean }\end{array}$ \\
\hline Joke & Information & 23 & 1.57 & 0.992 & 0.207 \\
Humorous & Humour & 23 & 2.48 & 0.898 & 0.187 \\
informative text & Information & 23 & 1.22 & 0.850 & 0.177 \\
Informative text & Humour & 23 & 1.17 & 0.388 & 0.081 \\
& Information & 23 & 1.26 & 0.541 & 0.113 \\
& Humour & 23 & 1.09 & 0.288 & 0.060 \\
\hline
\end{tabular}


Table 4. Differences in the assessment of texts preceded by the announcement of an informative text and a humorous text, experiment II

\begin{tabular}{lccccc}
\hline Type of text & $t$ & $d f$ & $\begin{array}{c}\text { Significance } \\
\text { (two-tailed) }\end{array}$ & $\begin{array}{c}\text { Difference of } \\
\text { the means }\end{array}$ & $\begin{array}{c}\text { Standard } \\
\text { error of } \\
\text { the difference }\end{array}$ \\
\hline Joke & -3.272 & 43.570 & 0.002 & -0.913 & 0.279 \\
$\begin{array}{l}\text { Humorous } \\
\text { informative text }\end{array}$ & 0.223 & 30.759 & 0.825 & 0.043 & 0.195 \\
\begin{tabular}{l} 
Informative text \\
\hline
\end{tabular} & 1.361 & 33.556 & 0.183 & 0.174 & 0.128 \\
\hline
\end{tabular}

The question is why the announcement of a humorous text results in a higher assessment of the funniness of the jokes when the jokes are presented immediately after the announcement. The answer resides in the research on anticipation, which reveals that every variable facilitating the processing of information should lead to an increased appeal of the stimulus, even if it is presented once (Winkielman, Hubert, \& Olszanowski, 2011). In our case, the variable facilitating the processing, i.e. increasing the smoothness of the processing, is the information that a humorous stimulus is to be presented and assessed. If such a stimulus (joke) then really appears, its assessment will be in accordance with the anticipation caused by the conviction that it will be a funny text. If, on the other hand, the presentation of the real stimulus - a joke - is preceded by the information that the recipient will be processing and assessing an informative text, then the recipient will be set on processing the content in the bona fide mode. The humorous message is either overlooked or treated as unwanted, as a different content is anticipated. The cognitive dissonance caused by the divergence of what the respondents expect and what really appears evokes discomfort. Paraphrasing the words of Forabosco (1991), the recipient has difficulty with the sense of intellectual mastery after the reception of a joke even if he understands the joke-specific logic (Ziv, 1984) since he entertains the conviction that there is an additional hidden meaning. He cannot suspend the natural attitude typical for the bona fide mode and process the meaning of the utterance exclusively in the non-bona fide mode.

In our research, the type of preannouncement was not reflected in the difference of assessment of a humorous informative text, as the intensity of the humorous content was not high and the text contained information in accordance with the instruction. When the respondents were informed that the text was to be processed in the non-bona fide mode they did so, but the 
text was not so funny that its funniness earned maximum scores. If the recipients were instructed as to the informative character of the text they found the informative content (which was contained in the text), but were also not surprised at having to assess the funniness of the text. Its humorous form could be assessed, but again the text was not so funny that it could achieve maximum scores.

The assessment of the funniness of informative texts was the same because the informative text with a small dose of humour was not very funny. The average results show that the funniness of the texts was in general assessed as rather low. This also included the jokes that were assessed higher after a humorous anticipation was created in the respondents.

The assessment of the funniness of texts of a certain form from the first and second experiment was also compared in both experimental groups with preceding information about the humorous and informative character of the texts. A difference was observed in the assessment of the humorous texts containing information. This type of text was always the second to appear, which is significant for the understanding of the observed effects. Higher assessments of humorous texts containing information were observed in the experimental situation in which the respondents were expecting to assess an informative text and the first text to appear was indeed an informative text with a small dose of humour. In accordance with earlier analyses, incongruence between the preceding information about how to process a text results in increased amusement and a higher assessment of the funniness of the relevant text.

When respondents anticipated the presentation of humorous texts, the funniness of humorous informative texts was assessed higher when jokes were presented first. This is due to the maintained positive attitude evoked by the announcement of a humorous text and its confirmation by the presentation of a joke.

The assessment of jokes also differed depending on the experiment. When an informative text was announced jokes received higher marks in the first experiment, where the informative text came at the beginning. As explained above, in this version of the experiment the jokes benefited from the surprise caused by the incongruence; the respondents simply were not expecting a joke.

On the other hand, when the assessment of the texts was preceded by an announcement of their humorous character, the funniness of the jokes was assessed higher in second experiment, where the jokes were presented first. This indicates that a positive anticipation of the reception of humorous stimuli was induced. In the first experiment, this humorous anticipation was diminished after the assessment of the informative text and the humorous informative text. 
Table 5. Comparison of the assessment of the texts preceded by the announcement of informative text

\begin{tabular}{llcccc}
\hline Type of text & Experiment & $N$ & Mean & $\begin{array}{c}\text { Standard } \\
\text { deviation }\end{array}$ & $\begin{array}{c}\text { Standard } \\
\text { error of } \\
\text { the mean }\end{array}$ \\
\hline Informative text & Experiment I & 22 & 1.14 & 0.351 & 0.075 \\
& Experiment II & 23 & 1.26 & 0.541 & 0.113 \\
Humorous & Experiment I & 22 & 1.73 & 0.767 & 0.164 \\
informative text & Experiment II & 23 & 1.22 & 0.850 & 0.177 \\
Joke & Experiment I & 22 & 2.50 & 0.964 & 0.205 \\
& Experiment II & 23 & 1.57 & 0.992 & 0.207 \\
\hline
\end{tabular}

Table 6. The differences in the text estimations in variant I and variant II with the preceding instruction about the informative text

\begin{tabular}{|c|c|c|c|c|c|}
\hline Type of text & $t$ & $d f$ & $\begin{array}{l}\text { Significance } \\
\text { (two-tailed) }\end{array}$ & $\begin{array}{l}\text { Difference of } \\
\text { the means }\end{array}$ & $\begin{array}{c}\text { Standard } \\
\text { error of } \\
\text { the difference }\end{array}$ \\
\hline Informative text & -0.920 & 37.950 & 0.364 & -0.125 & 0.135 \\
\hline $\begin{array}{l}\text { Humorous } \\
\text { informative text }\end{array}$ & 2.113 & 42.859 & 0.040 & 0.510 & 0.241 \\
\hline Joke & 3.206 & 42,988 & 0.003 & 0.935 & 0.292 \\
\hline
\end{tabular}

Table 7. Comparison of the assessment of the texts preceded by an announcement of humorous text

\begin{tabular}{llcccc}
\hline Type of text & Experiment & $N$ & Mean & $\begin{array}{c}\text { Standard } \\
\text { deviation }\end{array}$ & $\begin{array}{c}\text { Standard } \\
\text { error of } \\
\text { the mean }\end{array}$ \\
\hline Informative text & Experiment I & 17 & 1.18 & 0.393 & 0.095 \\
& Experiment II & 23 & 1.09 & 0.288 & 0.060 \\
Humorous & Experiment I & 17 & 1.71 & 0.849 & 0.206 \\
informative text & Experiment II & 23 & 1.17 & 0.388 & 0.081 \\
Joke & Experiment I & 17 & 1.53 & 0.717 & 0.174 \\
& Experiment II & 23 & 2.48 & 0.898 & 0.187 \\
\hline
\end{tabular}


Table 8. The differences in the text estimations in variant I and variant II with the preceding instruction about the humorous text

\begin{tabular}{lccccc}
\hline Type of text & $t$ & $d f$ & $\begin{array}{c}\text { Significance } \\
\text { (two-tailed) }\end{array}$ & $\begin{array}{c}\text { Difference of } \\
\text { the means }\end{array}$ & $\begin{array}{c}\text { Standard } \\
\text { error of } \\
\text { the difference }\end{array}$ \\
\hline $\begin{array}{l}\text { Informative text } \\
\begin{array}{l}\text { Humorous } \\
\text { informative text }\end{array}\end{array}$ & 0.795 & 28.023 & 0.434 & 0.090 & 0.113 \\
Joke & -3.712 & 37.722 & 0.001 & 0.532 & 0.221 \\
\hline
\end{tabular}

\section{Conclusions}

Agreement on the mode of communication between the sender and the recipient is not always clearly defined. Firstly, the sender does not always inform the recipient about the mode of their message, i.e. whether it will be in the bona fide mode or in the non-bona fide mode. The sender often assumes that their utterance is so explicit that the recipient should not have any problems understanding it. Due to the specificity of humorous messages, this assumption will not always find confirmation on account of the ambiguity of the humorous message. Due to this ambiguity the text may be received literally, or may result in the suspension of the "natural attitude" and the reference to joke-specific logic (Ziv, 1984). Secondly, even if the character of the message is clearly stated, there may be a problem with the construction of the message in a "pure" form. Thirdly, the recipient may have trouble reading the content, because they may not understand it and may have problems receiving it in the mode determined by the sender. Fourthly, the communication process is not always based on the rules defined by Grice. Participants of the communication process may intentionally introduce ambiguity, as this gives them the possibility to backtrack from the presented standpoint and hide their real intentions by pretending that the message is humorous. The intentional introduction of ambiguity and the concealment of the mode in which a message is constructed leads to false interpretations and assessments of the value of the given text.

In our research, we attempted to understand the mechanisms that disturb the process of communication when the mode of communication is not explicitly defined, or when the sender intentionally misleads the recipient as to the mode in which the message will be constructed. The results show that low comic intensity of humorous texts can be increased by not disclosing that they are intended 
to evoke an amusing effect. The humorous utterance then causes a surprise and is incongruent with the anticipation. This indicates the specific character of the humorous message, which produces an effect that is categorically not in accordance with the preceding stimulus. However, in order to produce such an effect certain conditions must be fulfilled. Other stimuli must be between the preceding and the assessed stimulus. If the stimulus to be assessed appears immediately after the preceding stimulus, the effect does not appear and only the stimuli belonging to the same semantic category are assessed. These observations coincide with the experiments conducted by Suls and Goldstein (1972) on the phenomenon of priming, namely that if we inform the recipient that a humorous text will shortly be presented then the text must appear immediately after this information. The created anticipation influences the relation to the immediately delivered stimulus, but is also maintained and projected onto the assessment of the following stimulus. Weakening of the comic intensity will result in the loss of the influence of the introductory stimulus. If the message that appears does not belong to the relevant semantic category and is not in accordance with the evoked emotional attitude, it will cause disappointment. If the target stimulus is delivered only afterwards, it will be more critically received.

According to the literature it can be assumed that the use of humorous messages requires that the stimulus is categorized as humorous (joke competence) and that it is appreciated (humour competence) (Carrell, 2000). Presumably, the stimulus must possess at least a minimum degree of comicality in order not to cause disappointment and in order not to achieve an adverse effect.

In the future it would be worthwhile to investigate if the structure and the content of the joke can also alter the results.

\section{References}

Brown, G. \& Yule, G. (1983). Discourse Analysis. Cambridge: Cambridge University Press.

Carrell, A. (2000). Two facets of communicative competence: Joke competence and humor competence. In S. Gajda \& D. Brzozowska (Eds.), Świat humoru [World of Humor] (pp. 27-36). Opole: Uniwersytet Opolski - Instytut Filologii Polskiej.

Dobek-Ostrowska, B. (2012). Komunikowanie publiczne i polityczne [Public and Political Communication]. Warszawa: Wydawnictwo Naukowe PWN.

Forabosco, G. (1991). Cognitive aspects of the humor process: The concept of incongruity. Humor, 5 (1-2), 45-68.

Goban-Klas, T. (2009). Media i komunikowanie masowe [Media and Massive Communication]. Warszawa: Wydawnictwo Naukowe PWN.

Goldstein, J.H., Suls, J.M., \& Anthony, S. (1972). Enjoment of specyfic types of humour content motivation or salience? In J.H. Goldstein \& P.E. McGhee (Eds.), The Psychology of Humor (pp. 159-171). New York: Academic Press. 
Grice, P. (1980). Logika a konwersacja [Logic and Conversation]. In B. Stanosz (Ed.), Język ws świetle nauki [Language in the Light of Science] (pp. 91-114). Warszawa: PWN.

Halliday, M.A.K. (1994). Introduction to functional grammar. London: Edward Arnold.

Morreale, S.P., Spitzberg, B.H., \& Barge, J.K. (2012). Komunikowanie między ludźmi [Human Communication: Motivation, Knowledge, Skills]. Warszawa: Wydawnictwo Naukowe PWN.

Nerhardt, G. (1970). Humor and inclination to laugh: Emotional reactions to stimuli of different divergence from a range of expectancy. Scandinavian Fournal of Psychology, 11 (1), 185-195.

Partington, A. (2006). The Linguistics of Laughter: A Corpus-Assisted Study of Laughter-Talk. New York: Routledge.

Raskin, V. (1985). Semantic Mechanisms of Humor. Dordrecht: D. Reidel Publishing Company.

Winkielman, P., Hubert, E.D., \& Olszanowski, M. (2011). Dynamiczne związki: rola płynności przetwarzania w afekcie i procesach wartościowania [Dynamic Relationships: The Role of Processing Fluency in Affect and in Valuation Processess]. In D. Doliński \& W. Błaszczak (Eds.), Dynamika emocji. Teoria i praktyka [Dynamics of Emotions. Theory and Practice] (pp. 60-87). Warszawa: Wydwawnictwo Naukowe PWN.

Zajdman, A. (1992). Did you mean to be funny? Well if you say so... Humor, $5(4), 357-368$.

Ziv, A. (1984). Personality and Sense of Humor. New York: Springer Publishing Company. 